\title{
Molecular mechanisms of opioid tolerance: From opioid receptors to inflammatory mediators (Review)
}

\author{
JIE ZHOU $^{1 *}$, RUIJIE MA $^{1 *}$, YING JIN $^{2}$, JUNFAN FANG $^{3}$, JUNYING DU $^{3}$, \\ XIAOMEI SHAO ${ }^{3}$, YI LIANG ${ }^{4}$ and JIANQIAO FANG ${ }^{4}$ \\ ${ }^{1}$ Department of Acupuncture and Moxibustion, The Third Affiliated Hospital of Zhejiang Chinese Medical University, \\ Hangzhou, Zhejiang 310005; ${ }^{2}$ Department of Rehabilitation in Traditional Chinese Medicine, \\ The Second Affiliated Hospital of Zhejiang University School of Medicine, Hangzhou, Zhejiang 310000; \\ ${ }^{3}$ The Third Clinical Medical College and ${ }^{4}$ Key Laboratory of Acupuncture and Neurology of Zhejiang Province, \\ Zhejiang Chinese Medical University, Hangzhou, Zhejiang 310053, P.R. China
}

Received September 26, 2020; Accepted April 19, 2021

DOI: $10.3892 /$ etm.2021.10437

\begin{abstract}
Opioids are considered the most effective analgesics for the treatment of both acute and chronic pain. However, prolonged opioid use can induce a certain level of tolerance to its analgesic effects, leading to a reduction in its effectiveness, addiction and abuse. A better understanding of the mechanisms underlying opioid tolerance may provide insights into this phenomenon and aid in the development of novel methods to combat the side effects of opioid tolerance. The present review focused on two major contributors to tolerance, opioid receptors and inflammatory mediators. The molecular mechanisms involved in the desensitization of the opioid receptors were briefly described, including their phosphorylation, internalisation and recycling. Subsequently, the effects of Toll like receptor 4/NOD-like receptor family pyrin domain containing 3-mediated proinflammatory responses in opioid tolerance were discussed, aiming in supporting the identification of novel therapeutic targets.
\end{abstract}

\section{Contents}

1. Introduction

2. Opioid receptors

Correspondence to: Professor Yi Liang or Professor Jianqiao Fang, Key Laboratory of Acupuncture and Neurology of Zhejiang Province, Zhejiang Chinese Medical University, 548 Binwen Road, Binjiang, Hangzhou, Zhejiang 310053, P.R. China

E-mail: liangyiwww@126.com

E-mail: fangjianqiao7532@163.com

*Contributed equally

Key words: pain, opioid tolerance, morphine, opioid receptors, proinflammatory cytokines, Toll like receptor 4, NOD-like receptor family pyrin domain containing 3 , neuroinflammation
3. Molecular mechanisms of opioid tolerance

4. Proinflammatory cytokines in morphine tolerance

5. Conclusions

\section{Introduction}

Pain is an important global health problem. Recent data suggest that $>30 \%$ of the population in China suffers from a form of chronic pain, including joint pain, headaches, severe back pain and cancer-related pain, with a low rate of treatment (1). The aetiology of pain is a complex, transdisciplinary process with multiple causes, including cancer, rheumatoid arthritis, spinal problems, injuries and surgery (2). Individuals who experience chronic pain usually have a reduced quality of life resulting from both the physical and mental toll of this condition. For instance, numerous individuals who suffer from chronic pain experience depression, anxiety and even suicidal thoughts (3). Opiates, which were discovered thousands of years ago, are to date the most common and effective analgesics for the treatment of pain and pain-associated disorders (4). Important progress has been made in the development of opioids derived from opiates in the last century, but several of their side effects persist (5). An Italian study revealed that the average duration of opioid treatment in patients with cancer is 105 days (6). Long-term opioid treatment results in decreased analgesic efficacy via increased tolerance and an increased potential for addiction (7).

Tolerance is defined as the reduction in the effects of a drug following its prolonged administration, leading to the loss of drug potency and the increase in dosage to maintain its analgesic effects (8). However, this increase in dosage may accelerate tolerance and its side effects, including respiratory depression, gastrointestinal immobility and addiction $(8,9)$. The drug interactions with opioid receptors and the dose and frequency of administration are the primary reasons for the development and extension of tolerance (10). Numerous mechanisms are involved in opioid tolerance, including the receptor downregulation and signalling desensitisation, upregulation of drug metabolism and initiation of 
compensatory/opponent processes (11). Because of the loss of the analgesic effect and the severity of the side effects, drug tolerance is one of the most challenging issues in the clinical application of opioids and can ultimately lead to poor patient compliance and treatment discontinuation (12). Thus, a better understanding of the molecular mechanisms underlying the development of opioid receptor tolerance, regulation and signal transduction may help in the identification of novel strategies to tackle these clinical problems.

Although it has been widely established that opioid drugs are critical to proper pain management and that their receptor desensitisation is closely associated with opioid tolerance, the role of inflammation and the associated molecular mechanisms in this phenomenon have not been well studied until relatively recently (13). A growing body of literature suggests that activated microglia and astrocytes (glia) are the primary targets in pain management, because of their function in pain transmission and opioid analgesia $(14,15)$. Morphine, one of the most effective analgesics, affects the glia through Toll like receptor 4 (TLR4), inducing proinflammatory cytokine production and increasing morphine tolerance (16). Due to its strong anti-analgesic effects and critical role in morphine tolerance, IL-1 $\beta$ stands out among the morphine-induced cytokines (17). Morphine treatment upregulates IL-1 $\beta$ production, and antagonisation of the IL-1 receptor reverses morphine tolerance (14). Thus, both the NOD-like receptor family pyrin domain containing 3 (NLRP3) inflammasome, a major signalling pathway involved in IL-1 $\beta$ release, and TLR4 signalling are receiving increasing attention for the regulation of morphine tolerance (18).

The present review summarized the current knowledge on the interactions between opioid systems and the function of inflammatory factors and their impact on the development of opioid tolerance. The cellular and molecular mechanisms involved in opioid tolerance and the inflammatory factors implicated in TLR4- and NLRP3-inflammasome-mediated tolerance responses were discussed. The aim of the current review was to reveal the full image of opioid receptors and inflammatory factors and their impact on opioid tolerance and aid in the identification of potential therapeutic targets for the enhancement of analgesic efficacy and the reduction of side effects in chronic pain management.

\section{Opioid receptors}

Opioid receptors are a class of seven-transmembrane-spanning inhibitory $\mathrm{G}$ protein-coupled receptors, with a high affinity for $\beta$-endorphin and enkephalins and a low affinity for dynorphins (19). They are widely expressed in the pain-modulating descending pathways of various tissues, including the brain, spinal cord, peripheral neurons and digestive tract (20). The activation of these receptors is critical for the analgesic effects of these drugs and is achieved via the direct inhibition of the spinal cord neurons, preventing pain signalling in the spinal cord $(7,21)$. There are four different types of opioid receptors related to analgesia: $\mu$ opioid receptors (MORs), $\delta$ opioid receptors (DORs), $\kappa$ opioid receptors (KORs) and opioid receptor like-1 (ORL-1), which are all well characterised at both the molecular and pharmacological levels (22) (Table I).
MORs. MORs are the most common and well-studied opioid receptors in pain management. MORs were the first opioid receptors identified in 1973 (23). In 2012, the first X-ray crystal structure of the murine MOR was characterised. It revealed significant detail about ligand and receptor binding patterns, providing valuable insights for the identification of novel bioactive molecules and the development of better drugs for pain management (24). The phosphorylation of MORs is one of the most significant methods of receptor internalisation and desensitisation, eventually causing opioid tolerance (25). There are $>15$ serine, threonine and tyrosine residues in MORs, which are accessible for phosphorylation by various protein kinases (26). Ser375 at the C-terminus of the rat MOR is phosphorylated to varying degrees upon treatment with both morphine and [D-Ala ${ }^{2}, \mathrm{~N}-\mathrm{MePhe}^{4}$, Gly-ol]-enkephalin (DAMGO; a strong synthetic agonist of MORs) (27). Another study has indicated that the phosphorylation of Tyr166 inhibited the $\mathrm{G}$ protein activation mediated by DAMGO (28). In addition, multi-phosphorylation in the specific region of the C-terminal tail of MORs has also been demonstrated to be involved in the endocytosis of MORs (29). Both point mutations and alanine substitution of the serine and threonine residues from 375 to 379 (STANT sequence) has been indicated to markedly decrease the agonist-induced recruitment of $\beta$-arrestin and receptor internalisation. However, this did not eliminate the induction of acute desensitisation (29-31), suggesting that multiple amino acid residues are involved in the regulation of MORs. These ligand-mediated differences also indicated that receptor regulation and trafficking vary depending on the agonist and require further elucidation.

DORs. Numerous studies have revealed that DORs and MORs directly interact with each other to form heteromers, which have been confirmed via co-immunoprecipitation $(32,33)$. Interestingly, DOR agonists not only activate DORs, but also induce MOR internalisation and degradation, thereby inhibiting MOR agonist activity and inducing morphine tolerance (34). It has been suggested that blocking DOR function via gene knockout or DOR antagonists may reduce morphine tolerance $(33,35-38)$. However, DOR knockout in mice presented conflicting results with either no alteration (39) or in certain cases, reduced morphine analgesic effects (40). This may be due to the high amino acid sequence similarity $(\sim 60 \%)$ in murine DOR and MOR proteins. High doses of their specific ligands can bind to both receptors and enhance the analgesic effect (35). Similar to MORs, phosphorylation of the C-terminal residues results in DOR desensitisation and regulation. G protein-coupled receptor kinase (GRK) 2 phosphorylates the Ser363 residue, which is a key event in DOR regulation (41). Thr353, at the $\mathrm{COOH}$-terminal tail, is critical for the downregulation of DORs in response to [D-Ala ${ }^{2}$, D-Leu ${ }^{5}$ ]-enkephalin (42). The phosphorylation of Thr161 by cyclin-dependent kinase 5 is required for DOR expression and the production of MOR-DOR heterodimers (43), and serves an important role in the development of morphine tolerance. Taken together, these studies suggested that DOR phosphorylation may attenuate opioid tolerance during pain management.

KORs. KORs represent another appealing therapeutic target activated by endogenous dynorphin, a specific endogenous 
ligand of KOR. KORs are phosphorylated, desensitised and internalised by their agonists (44). Salvinorin A, nalfurafine hydrochloride and type II thioesterase from the rifamycin biosynthetic pathway, which are three structurally distinct kappa ligands, induce KOR internalisation in a dose-dependent manner with different potency rankings (45). The phosphorylation of Ser369 mediated by GRK and $\beta$-arrestin binding causes KOR desensitisation and sustains analgesic tolerance. These results were confirmed both in vitro in transfected cells and in vivo using mice (46). In addition to its analgesic benefit, KOR signalling also plays several other important roles across the nervous system. It is involved in the mediation of negative emotional states, such as drug reinstatement, depression and aversion (47-50), and its natural agonist, salvinorin A, functions as a psychoactive drug $(51,52)$.

ORL-1. ORL-1 is also known as the nociception opioid peptide receptor. It is the most recently discovered opioid receptor and is known to bind to its natural ligand nociceptin, a 17-amino acid neuropeptide (53). Although ORL-1 shares high sequence identity with the classical opioid receptors $(\mu, \delta$ and $\kappa)$, ORL-1 ligands possess low affinity for these other opioid receptors $(54,55)$. Reciprocally, agonists of the classic opioid receptors, such as opioid peptides or morphine-like compounds, possess low or no affinity for ORL-1 (56). Both nociceptin and the ORL-1 agonist Ro646198 induce rapid internalisation of ORL-1 in a concentration-dependent manner within minutes of exposure, much faster than that of the other three receptors (57), although they share a similar internalisation mechanism. ORL-1 plays a critical role in the regulation of several brain activities, including instinctive and emotional behaviours (53). Studies on ORL-1 have indicated its potential therapeutic use for non-addictive painkillers, depression and Parkinson's disease in the future (58).

\section{Molecular mechanisms of opioid tolerance}

The molecular mechanisms underlying in vivo opioid tolerance remain uncertain; however, numerous studies have proposed that the regulation of opioid receptors via mechanisms, such as desensitisation, phosphorylation, $\beta$-arrestin binding, endocytosis, re-sensitisation and recycling, is involved in the development of opioid tolerance (Fig. 1). For example, when the receptors are activated by the endogenous $\mu$-opioid peptide endorphin or exogenous opioid agonists, such as morphine, the $\mathrm{G} \alpha$ and $\mathrm{G} \beta \gamma$ subunits dissociate from each other and bind to potassium and calcium channels. This mechanism modulates voltage activation, inwardly rectifies the potassium channels and inhibits calcium conductance, inducing cellular hyperpolarisation and inhibiting tonic neural activity (59-61). A previous study using in vitro and in vivo model systems have demonstrated that the primary action of opioid receptors is to positively regulate potassium channels and negatively modulate calcium channels in the nervous system, from neurons in the hippocampus to the dorsal root ganglia (62). Subsequently, MORs are phosphorylated by GRK at different amino acid residues, with a saturation time of $<20 \mathrm{sec}$ (25). In addition, $\beta$-arrestin serves a critical role in the development of opioid tolerance. In mice, lack of $\beta$-arrestin- 2 enhanced morphine analgesic function and attenuated the development of morphine 


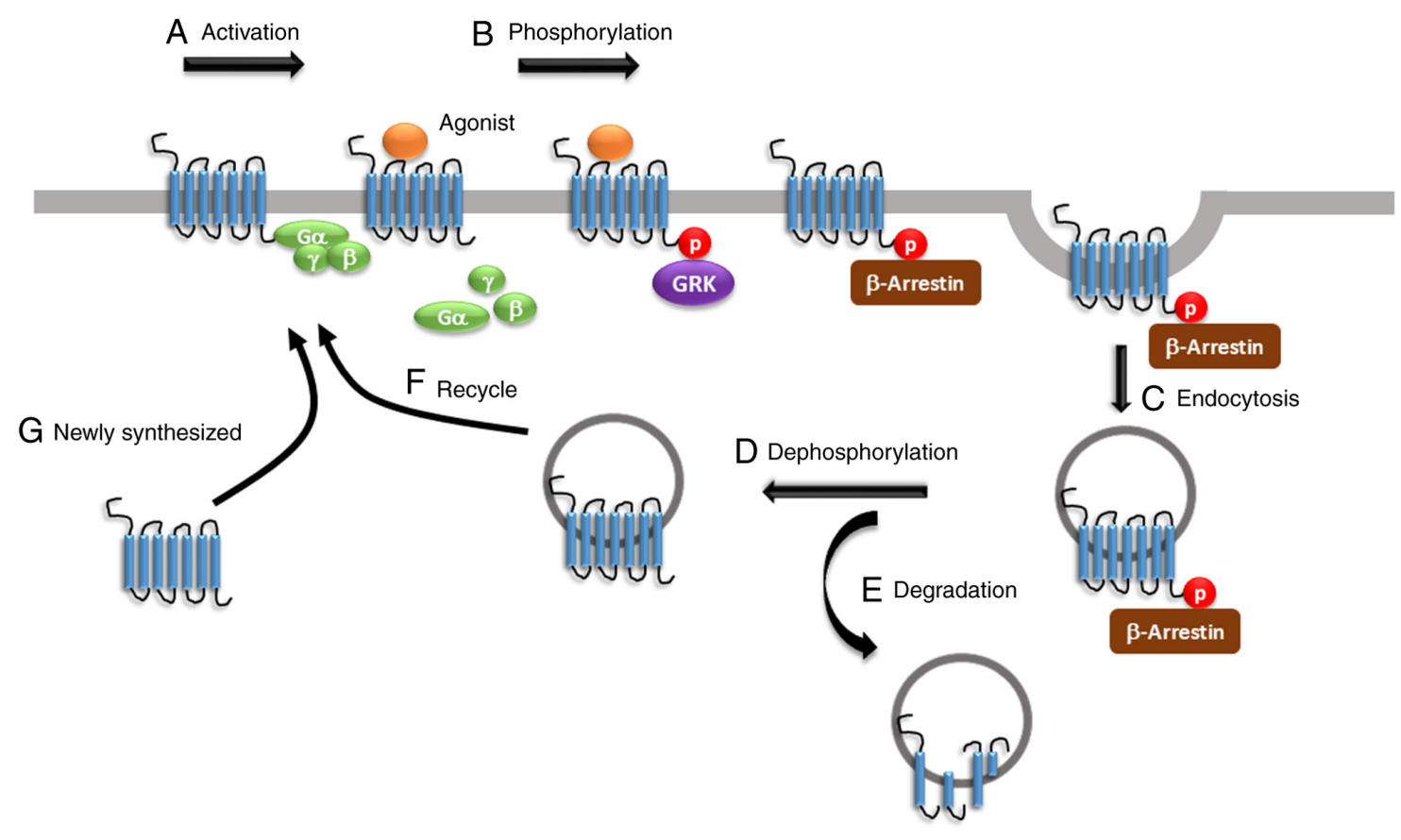

Figure 1. Regulation of MORs. (A) The activation of MORs is dependent on the binding of agonist to receptors. (B) After binding, G $\alpha$ and G $\beta \gamma$ subunits dissociate from each other. GRKs phosphorylate receptors. After phosphorylation, $\beta$-arrestin is recruited to the ligand-receptor complex to prevent further G-protein coupling. (C) The receptors together with $\beta$-arrestin then undergo endocytosis into the early endosomes, which is called receptor internalization. Receptors can be (D) dephosphorylated and (E) degraded by lysosomes or (F) resensitized through trafficking back to the cell membrane. (G) The newly synthesized receptors are transferred to the membrane for further ligand-receptor activation. MOR, $\mu$ opioid receptor; GRK, G protein-coupled receptor kinase; p, phosphorylated.

tolerance (63). The phosphorylation of the GRK family and $\beta$-arrestin binding triggers clathrin-dynamin-mediated MOR endocytosis (25). In addition, arrestin-dependent internalisation is considered the first step in receptor recovery following desensitisation, resulting in the translocation of reactivated receptors to the plasma membrane through recycling. This event is known as resensitisation (25). A reduction in opioid receptor numbers, resulting from a decrease in receptor synthesis or receptor internalisation followed by degradation, also contributes to opioid tolerance (25). In vivo studies indicated that chronic treatment with opioids promoted the downregulation and upregulation of opioid receptors (64-66), with tolerance usually associated with receptor downregulation.

\section{Proinflammatory cytokines in morphine tolerance}

The two possible mechanisms involved in drug tolerance are within-system and between-system adaptation (67). Within-system drug tolerance occurs when opposite reactions are elicited within the same system. A recent study has indicated that chronic morphine use induced a shift in MOR signalling from the predominantly inhibitory Gi/Go adenylyl cyclase to the stimulatory Gs adenylyl cyclase through the upregulation of different MOR receptor variants (68). Specifically, chronic morphine use induced the phosphorylation of the carboxyl terminal sites on MOR-1B2 and MOR-1C1, enhancing Gs protein association (68). In between-system adaptation, different drug-sensitive systems are linked to the drugs' primary action system. Neuroinflammation and the release of proinflammatory cytokines, as well as innate immune signalling, such as TLR4- and NLRP3-mediated inflammasomes, are the key molecular mechanisms for between-system adaptation (Fig. 2) (69).

Glial cells are activated by cytokines in the central nervous system and release other mediators that trigger neuroinflammation (70). IL-1 $\beta$, a key proinflammatory cytokine, plays an important role in host defence and inflammation and is a critical mediator of inflammatory pain and opioid analgesia (71). In a mouse study, the administration of IL-1 $\beta$ abolished morphine analgesia, and genetic or pharmacological inhibition of IL-1 signalling prevented the development of morphine tolerance (72). Prolonged morphine treatment was indicated to induce glial TLR4 activation, which promoted neurotoxicity and amplified nociceptive signalling in the spinal cord (73). Moreover, chronic morphine use activated TLR4 signalling in the brain, especially in the periaqueductal grey region, resulting in changes in inflammatory cytokine expression, thereby inducing glutamatergic signalling and eventually leading to opioid tolerance (74). Expression of IL-1 $\beta$ could also be induced by morphine via activated microglia, which disrupted glutamate homeostasis by downregulating glutamate transporter 1 and increasing glutamate, thereby triggering the release of ATP from the glia. These events may contribute to excitotoxicity and chronic inflammation, which leads to continued morphine discontinuation (75). Interestingly, IL-1 $\beta$ treatment significantly upregulated MOR mRNA expression in various cell types, including primary astrocytes, neurons and microvascular endothelial cells, which further supports the interaction between IL-1 $\beta$ and the opioid system (76,77). In addition, other inflammatory cytokines, such as TNF- $\alpha$, IFN- $\alpha$, IL-4 and IL-6 are also associated with MOR expression in neural and immune cells (78). IL-1 $\beta$ mediates its function through IL-1 


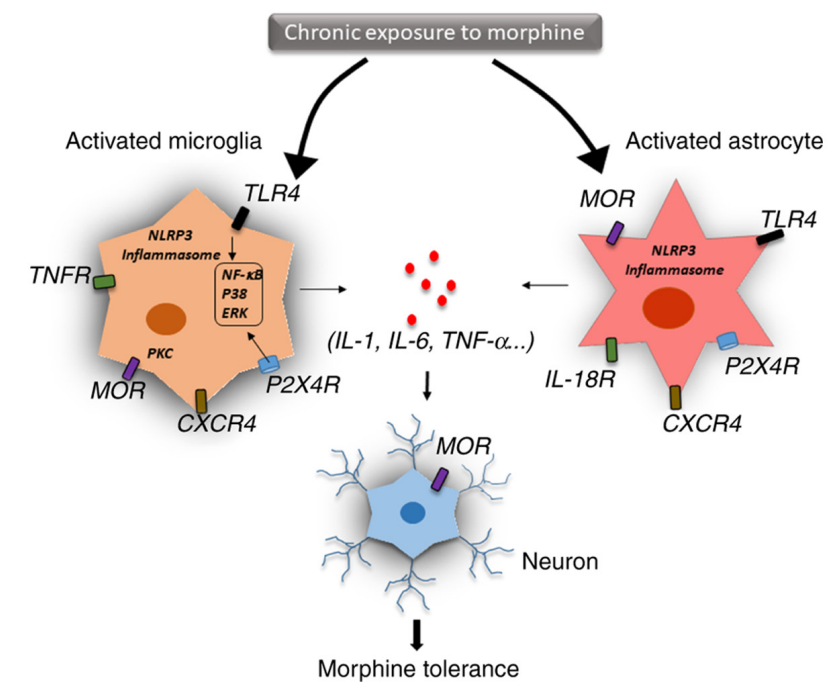

Figure 2. Central immune mechanisms of opioid tolerance. Neuroinflammation and the release of proinflammatory cytokines are the key factors of the central immune mechanisms of opioid tolerance. After chronic exposure to morphine, microglia and astrocytes are activated via different immune signalling pathways. Activation of TLR4/NF- $\kappa \mathrm{B}$ signalling, the NLRP3-dependent inflammasome and the purinergic receptor P2X4R have been demonstrated to induce the production of proinflammatory cytokines, such as TNF $\alpha$, IL-18, IL-1 $\beta$ and IL-6, in microglia and astrocytes. These inflammatory cytokines are associated with alteration of the MOR level in neural and other immune cells. Cytokine production is mainly mediated by $\mathrm{NF}-\kappa \mathrm{B}$ activation, p38 phosphorylation and ERK signalling. IL-18 derived from microglia signals through IL-18R, resulting in D-serine release from astrocytes, which then induces $\mathrm{N}$-methyl-D-aspartate receptor activation in neurons. The chemokine receptor CXCR4 induces desensitization of MORs in neurons, leading to opioid tolerance. TLR4, toll-like receptor 4; NLRP3, NOD-like receptor family pyrin domain containing 3; P2X4R, P2X purinoceptor 4; MOR, $\mu$ opioid receptor; CXCR4, C-X-C chemokine receptor type 4; TNFR, TNF receptor; IL-18R, IL-18 receptor.

receptor type 1 protein (78). Previous studies have indicated that IL-1 $\beta$ stimulation activated downstream signalling, including the janus kinase-STAT, MAPK and NF- $\kappa$ B pathways, which altered MOR transcriptional level $(79,80)$. Chronic morphine treatment has been indicated to upregulate purinergic $\mathrm{P} 2 \mathrm{X} 7$ receptor $(\mathrm{P} 2 \mathrm{X} 7 \mathrm{R})$ and increase the expression of IL-18 in the microglia, IL-18 receptor in astrocytes and protein kinase $\mathrm{C} \gamma$ $(\mathrm{PKC} \gamma)$ in neurons of the spinal dorsal horn. Thus, targeting the P2X7R/IL-18/PKC $\gamma$ cascade may present a novel therapeutic target for reducing and understanding morphine tolerance in the clinical management of chronic pain (81).

Since IL-1 $\beta$ and IL-18 are both classical cytokines released during inflammasome activation, TLR4 and NLRP3 signalling may be critical for opioid tolerance and should be investigated more thoroughly (18). TLR4, a member of the toll-like receptor family, can recognise specific danger-associated molecular patterns and initiate an immune response $(82,83)$. A previous study reported that morphine resulted in microglial activation via TLR4/myeloid differentiation factor 2 binding (84). Blocking TLR4 signalling inhibited microglial activation, attenuated morphine tolerance and facilitated pain management (85). It is well understood that TLR4 functions as a prime signal that triggers downstream signalling pathways, enhancing the transcription of NLRP3 and pro-IL-1 $\beta$ (86). Subsequently, a second signal triggers several NLRP3 subunits into forming a protein complex known as the inflammasome, which then recruits caspase-1, and eventually leads to the maturation and secretion of IL-1 $\beta$ and IL-18 (87). Numerous studies have suggested that the NLRP3 inflammasome plays an important role in pain conditions, such as post-herpetic neuralgia, postoperative pain and neuropathic pain through secreted proinflammatory cytokines $(88,89)$. It has been demonstrated that inhibition of the NLRP3 inflammasome attenuated morphine tolerance (90). A previous study reported that morphine activated the potassium ATP channel, and blocking this channel alleviated morphine tolerance by inhibiting the heat shock protein 70/TLR4/NLRP3 cascade-mediated neuroinflammation (91). Taken together, these results suggested that TLR4/NLRP3 inflammasome-mediated neuroinflammation is critical for morphine tolerance and pain management.

\section{Conclusions}

The present review summarized the underlying molecular mechanisms of opioid tolerance facilitated by both within-system and between-system regulation. Agonist activation results in the phosphorylation of the opioid receptors by various kinases, including GRK and PKC, leading to $\mathrm{G}$ protein uncoupling, $\beta$-arrestin binding, receptor desensitisation and endocytosis, followed by degradation or recycling. Drugs targeting opioid receptors and inhibiting $\mathrm{G}$ protein dissociation or $\beta$-arrestin binding are still in preclinical or early clinical studies designed to evaluate their impact on opioid tolerance (25). Interestingly, prolonged opioid treatment accelerates the production and secretion of proinflammatory cytokines, such as IL-1 $\beta$ and IL-18, which suppress morphine analgesia and lead to opioid tolerance (14). Inflammatory immune responses are considered a critical contributor to the regulation of the opioid receptors. Numerous studies have suggested that suppression of the TLR4/NLRP3-mediated inflammasome activation and the inflammatory response in microglia lead to an important attenuation of morphine tolerance (18). Taken together, these results could reveal novel therapeutic targets of anti-opioid tolerance, from opioid receptors to inflammatory factors. Several studies have indicated that inflammatory factors promote morphine tolerance; however, how inflammatory factors act on opioid receptors and how they affect opioid analgetic tolerance is still unknown $(8,78,92)$. A better understanding of the association between inflammatory factors and opioid receptors will help understand the mechanism underlying opioid resistance and assist in the identification of potential therapeutic targets, the development of anti-opioid drugs and the treatment of its side effects. There is abundant basic information describing the mechanism and treatment of morphine tolerance, but there are few clinical trials completed to draw definitive conclusions (93), indicating that there is still a lack of effective measures and methods to inhibit morphine tolerance. Multicentre randomised controlled clinical trials are needed in the future. With the development of biomarkers and genetic diagnostic tests, opioid treatment could be personalized, which may aid in addressing opioid tolerance and improving therapeutic outcomes for individual patients. With a deepened understanding of the opioid lifecycle and the underlying molecular mechanisms of morphine tolerance, more effective drugs with fewer side effects may be produced in the future. 


\section{Acknowledgements}

Not applicable.

\section{Funding}

The present study was supported by Natural Science Foundation of Zhejiang Province (grant nos. LQ21H270008 and LQ18H270001), Zhejiang Province Top Discipline of Chinese Medicine (grant no. ZTK2017A02) and Innovation Fund for Youth of Zhejiang Chinese Medical University (grant no. KC201947).

\section{Availability of data and materials}

Not applicable.

\section{Authors' contributions}

JZ led the present review. YJ, YL and JiF contributed to the conception of the review. JZ and YL developed the research methods, according to the comments and feedback from YL and RM. JZ, JuF and XS performed the literature search and applied the selection criteria. JZ and RM synthesised the data and wrote the first draft of the manuscript. RM, JD and JiF contributed to the modification of the first draft of the manuscript. Data authentication is not applicable. All authors have read and approved the final manuscript.

\section{Ethics approval and consent to participate}

Not applicable.

\section{Patient consent for publication}

Not applicable.

\section{Competing interests}

The authors declare that they have no competing interests.

\section{References}

1. Yongjun Z, Tingjie Z, Xiaoqiu Y, Zhiying F, Feng Q, Guangke X, Jinfeng L, Fachuan N, Xiaohong J and Yanqing L: A survey of chronic pain in China. Libyan J Med 15: 1730550, 2020.

2. Mills SEE, Nicolson KP and Smith BH: Chronic pain: A review of its epidemiology and associated factors in population-based studies. Br J Anaesth 123: e273-e283, 2019.

3. Strand EB, Mengshoel AM,Sandvik L, Helland IB, Abraham S and Nes LS: Pain is associated with reduced quality of life and functional status in patients with Myalgic Encephalomyelitis/Chronic Fatigue Syndrome. Scand J Pain 19: 61-72, 2019.

4. Chou R, Hartung D, Turner J, Blazina I, Chan B, Levander X, McDonagh M, Selph S, Fu R and Pappas M: Opioid Treatments for Chronic Pain. Agency for Healthcare Research and Quality (US), Rockville, MD, 2020.

5. Daoust R, Paquet J, Cournoyer A, Piette E, Morris J, Lessard J, Castonguay V, Williamson D and Chauny JM: Side effects from opioids used for acute pain after emergency department discharge. Am J Emerg Med 38: 695-701, 2020.

6. Roggeri D, Saramin C, Terrazzani G, Zusso M, Giusti P and Chinellato A: Resource consumption and costs of treating pain in patients affected by cancer in a district of northeast Italy. Pharmacol Res 56: 329-334, 2007.
7. Ahlbeck K: Opioids: A two-faced Janus. Curr Med Res Opin 27: 439-448, 2011.

8. Eidson LN and Murphy AZ: Inflammatory mediators of opioid tolerance: Implications for dependency and addiction. Peptides 115: 51-58, 2019.

9. Gulur P, Williams L, Chaudhary S, Koury K and Jaff M: Opioid tolerance-a predictor of increased length of stay and higher readmission rates. Pain Physician 17: E503-E507, 2014.

10. Martyn JAJ, Mao J and Bittner EA: Opioid tolerance in critical illness. N Engl J Med 380: 365-378, 2019.

11. Allouche S, Noble F and Marie N: Opioid receptor desensitization: Mechanisms and its link to tolerance. Front Pharmacol 5: 280, 2014.

12. Rosenblum A, Marsch LA, Joseph H and Portenoy RK: Opioids and the treatment of chronic pain: Controversies, current status, and future directions. Exp Clin Psychopharmacol 16: 405-416, 2008.

13. Uniyal A, Gadepalli A, Akhilesh and Tiwari V: Underpinning the neurobiological intricacies associated with opioid tolerance. ACS Chem Neurosci 11: 830-839, 2020.

14. Liang Y, Chu H, Jiang Y and Yuan L: Morphine enhances IL-1 $\beta$ release through toll-like receptor 4-mediated endocytic pathway in microglia. Purinergic Signal 12: 637-645, 2016.

15. Sanna MD, Borgonetti V and Galeotti N: $\mu$ Opioid receptor-triggered notch-1 activation contributes to morphine tolerance: Role of neuron-glia communication. Mol Neurobiol 57: 331-345, 2020.

16. Wang X, Loram LC, Ramos K, de Jesus AJ, Thomas J, Cheng K, Reddy A, Somogyi AA, Hutchinson MR, Watkins LR and Yin H: Morphine activates neuroinflammation in a manner parallel to endotoxin. Proc Natl Acad Sci USA 109: 6325-6330, 2012.

17. Johnston IN, Milligan ED, Wieseler-Frank J, Frank MG,Zapata V, Campisi J, Langer S, Martin D, Green P, Fleshner M, et al: A role for proinflammatory cytokines and fractalkine in analgesia, tolerance, and subsequent pain facilitation induced by chronic intrathecal morphine. The Journal of neuroscience: J Neurosci 24: 7353-7365, 2004.

18. Wang H, Zhang Y, Ma X, Wang W, Xu X, Huang M, Xu L, Shi H, Yuan T, Jiang W, et al: Spinal TLR4/P2X7 receptor-dependent NLRP3 inflammasome activation contributes to the development of tolerance to morphine-induced antinociception. J Inflamm Res 13: 571-582, 2020.

19. Pasternak GW and Pan YX: Mu opioids and their receptors: Evolution of a concept. Pharmacol Rev 65: 1257-1317, 2013.

20. Yam MF, Loh YC, Tan CS, Khadijah Adam S, Abdul Manan N and Basir R: General pathways of pain sensation and the major neurotransmitters involved in pain regulation. Int J Mol Sci 19: 2164, 2018.

21. McNicol E, Horowicz-Mehler N, Fisk RA, Bennett K, Gialeli-Goudas M, Chew PW, Lau J and Carr D; Americal Pain Society: Management of opioid side effects in cancer-related and chronic noncancer pain: A systematic review. J Pain 4: 231-256, 2003.

22. Dougall IG: A critical review of the classification of opioid receptors. Biotechnol Appl Biochem 10: 488-499, 1988.

23. Pert CB and Snyder SH: Opiate receptor: Demonstration in nervous tissue. Science 179: 1011-1014, 1973.

24. Manglik A, Kruse AC, Kobilka TS, Thian FS, Mathiesen JM, Sunahara RK, Pardo L, Weis WI, Kobilka BK and Granier S: Crystal structure of the micro-opioid receptor bound to a morphinan antagonist. Nature 485: 321-326, 2012.

25. Williams JT, Ingram SL, Henderson G, Chavkin C, von Zastrow M, Schulz S, Koch T, Evans CJ and Christie MJ: Regulation of $\mu$-opioid receptors: Desensitization, phosphorylation, internalization, and tolerance. Pharmacol Rev 65: 223-254, 2013.

26. Chavkin C, McLaughlin JP and Celver JP: Regulation of opioid receptor function by chronic agonist exposure: Constitutive activity and desensitization. Mol Pharmacol 60: 20-25, 2001.

27. Schulz S, Mayer D, Pfeiffer M, Stumm R, Koch T and Hollt V: Morphine induces terminal micro-opioid receptor desensitization by sustained phosphorylation of serine-375. EMBO J 23: 3282-3289, 2004.

28. Clayton CC, Bruchas MR, Lee ML and Chavkin C: Phosphorylation of the mu-opioid receptor at tyrosine 166 (Tyr3.51) in the DRY motif reduces agonist efficacy. Mol Pharmacol 77: 339-347, 2010.

29. Lau EK, Trester-Zedlitz M, Trinidad JC, Kotowski SJ, Krutchinsky AN, Burlingame AL and von Zastrow M: Quantitative encoding of the effect of a partial agonist on individual opioid receptors by multisite phosphorylation and threshold detection. Sci Signal 4: ra52, 2011. 
30. Arttamangkul S, Heinz DA, Bunzow JR, Song $X$ and Williams JT: Cellular tolerance at the micro-opioid receptor is phosphorylation dependent. Elife 7: e34989, 2018.

31. Birdsong WT, Arttamangkul S, Bunzow JR and Williams JT: Agonist binding and desensitization of the $\mu$-opioid receptor is modulated by phosphorylation of the C-terminal tail domain. Mol Pharmacol 88: 816-824, 2015.

32. Fan T, Varghese G, Nguyen T, Tse R, O'Dowd BF and George SR: A role for the distal carboxyl tails in generating the novel pharmacology and $\mathrm{G}$ protein activation profile of mu and delta opioid receptor hetero-oligomers. J Biol Chem 280: 38478-38488, 2005.

33. Gomes I, Gupta A, Filipovska J, Szeto HH, Pintar JE and Devi LA: A role for heterodimerization of mu and delta opiate receptors in enhancing morphine analgesia. Proc Natl Acad Sci USA 101: 5135-5139, 2004.

34. He SQ, Zhang ZN, Guan JS, Liu HR, Zhao B, Wang HB, Li Q, Yang H, Luo J, Li ZY, et al: Facilitation of $\mu$-opioid receptor activity by preventing $\delta$-opioid receptor-mediated codegradation. Neuron 69: 120-131, 2011

35. Wang D, Tawfik VL, Corder G, Low SA, Francois A, Basbaum AI and Scherrer G: functional divergence of delta and mu opioid receptor organization in CNS pain circuits. Neuron 98: 90-108, e5, 2018.

36. Chefer VI and Shippenberg TS: Augmentation of morphine-induced sensitization but reduction in morphine tolerance and reward in delta-opioid receptor knockout mice. Neuropsychopharmacology 34: 887-898, 2009.

37. Fujita W, Gomes I and Devi LA: Heteromers of $\mu$ - $\delta$ opioid receptors: new pharmacology and novel therapeutic possibilities. $\mathrm{Br}$ J Pharmacol 172: 375-387, 2015.

38. Schiller PW: Opioid peptide-derived analgesics. AAPS J 7 : E560-E565, 2005.

39. Scherrer G, Imamachi N, Cao YQ, Contet C, Mennicken F, O'Donnell D, Kieffer BL and Basbaum AI: Dissociation of the opioid receptor mechanisms that control mechanical and heat pain. Cell 137: 1148-1159, 2009.

40. Zhu Y, King MA, Schuller AG, Nitsche JF, Reidl M, Elde RP, Unterwald E, Pasternak GW and Pintar JE: Retention of supraspinal delta-like analgesia and loss of morphine tolerance in delta opioid receptor knockout mice. Neuron 24: 243-252, 1999.

41. Guo J, Wu Y, Zhang W, Zhao J, Devi LA, Pei G and Ma L: Identification of $\mathrm{G}$ protein-coupled receptor kinase 2 phosphorylation sites responsible for agonist-stimulated delta-opioid receptor phosphorylation. Mol Pharmacol 58: 1050-1056, 2000.

42. Al-Hasani R and Bruchas MR: Molecular mechanisms of opioid receptor-dependent signaling and behavior. Anesthesiology 115: 1363-1381, 2011

43. Xie WY, He Y, Yang YR, Li YF, Kang K, Xing BM and Wang Y: Disruption of Cdk5-associated phosphorylation of residue threonine-161 of the delta-opioid receptor: Impaired receptor function and attenuated morphine antinociceptive tolerance. J Neurosci 29: 3551-3564, 2009.

44. Jean-Charles PY, Kaur S and Shenoy SK: G Protein-coupled receptor signaling through $\beta$-arrestin-dependent mechanisms. J Cardiovasc Pharmacol 70: 142-158, 2017.

45. Wang Y, Tang K, Inan S, Siebert D, Holzgrabe U, Lee DY, Huang P, Li JG, Cowan A and Liu-Chen LY: Comparison of pharmacological activities of three distinct kappa ligands (Salvinorin A, TRK-820 and 3FLB) on kappa opioid receptors in vitro and their antipruritic and antinociceptive activities in vivo. J Pharmacol Exp Ther 312: 220-230, 2005.

46. McLaughlin JP, Myers LC, Zarek PE, Caron MG, Lefkowitz RJ, Czyzyk TA, Pintar JE and Chavkin C: Prolonged kappa opioid receptor phosphorylation mediated by G-protein receptor kinase underlies sustained analgesic tolerance. J Biol Chem 279: 1810-1818, 2004.

47. Lalanne L, Ayranci G, Kieffer BL and Lutz PE: The kappa opioid receptor: From addiction to depression, and back. Front Psychiatry 5: 170, 2014.

48. Lutz PE and Kieffer BL: Opioid receptors: Distinct roles in mood disorders. Trends Neurosci 36: 195-206, 2013.

49. Nygard SK, Hourguettes NJ, Sobczak GG, Carlezon WA and Bruchas MR: Stress-induced reinstatement of nicotine preference requires dynorphin/kappa opioid activity in the basolateral amygdala. J Neurosci 36: 9937-9948, 2016.

50. Taylor GT and Manzella F: Kappa opioids, salvinorin a and major depressive disorder. Curr Neuropharmacol 14: 165-176, 2016.

51. Sheffler DJ and Roth BL: Salvinorin A: The 'magic mint' hallucinogen finds a molecular target in the kappa opioid receptor. Trends Pharmacol Sci 24: 107-109, 2003.
52. Chavkin C, Sud S, Jin W, Stewart J, Zjawiony JK, Siebert DJ, Toth BA, Hufeisen SJ and Roth BL: Salvinorin A, an active component of the hallucinogenic sage salvia divinorum is a highly efficacious kappa-opioid receptor agonist: Structural and functional considerations. J Pharmacol Exp Ther 308: 1197-1203, 2004.

53. Mollereau C and Mouledous L: Tissue distribution of the opioid receptor-like (ORL1) receptor. Peptides 21: 907-917, 2000.

54. Thompson AA, Liu W, Chun E, Katritch V, Wu H, Vardy E, Huang XP, Trapella C, Guerrini R, Calo G, et al: Structure of the nociceptin/orphanin FQ receptor in complex with a peptide mimetic. Nature 485: 395-399, 2012.

55. Chen Y, Fan Y, Liu J, Mestek A, Tian M, Kozak CA and Yu L: Molecular cloning, tissue distribution and chromosomal localization of a novel member of the opioid receptor gene family. FEBS Lett 347: 279-283, 1994.

56. Mogil JS and Pasternak GW: The molecular and behavioral pharmacology of the orphanin $\mathrm{FQ} /$ nociceptin peptide and receptor family. Pharmacol Rev 53: 381-415, 2001.

57. Spampinato S, Baiula M and Calienni M: Agonist-regulated internalization and desensitization of the human nociceptin receptor expressed in CHO cells. Curr Drug Targets 8: 137-146, 2007.

58. Zaveri NT: Nociceptin opioid receptor (NOP) as a therapeutic target: Progress in translation from preclinical research to clinical utility. J Med Chem 59: 7011-7028, 2016.

59. Zamponi GW and Snutch TP: Modulating modulation: Crosstalk between regulatory pathways of presynaptic calcium channels. Mol Interv 2: 476-478, 2002

60. Zamponi GW and Snutch TP: Modulation of voltage-dependent calcium channels by $\mathrm{G}$ proteins. Curr Opin Neurobiol 8: 351-356, 1998.

61. Torrecilla M, Quillinan N, Williams JT and Wickman K: Preand postsynaptic regulation of locus coeruleus neurons after chronic morphine treatment: A study of GIRK-knockout mice. Eur J Neurosci 28: 618-624, 2008.

62. Diaz A, Florez J, Pazos A and Hurle MA: Opioid tolerance and supersensitivity induce regional changes in the autoradiographic density of dihydropyridine-sensitive calcium channels in the rat central nervous system. Pain 86: 227-235, 2000.

63. Bohn LM, Lefkowitz RJ and Caron MG: Differential mechanisms of morphine antinociceptive tolerance revealed in (beta) arrestin-2 knock-out mice. J Neurosci 22: 10494-10500, 2002.

64. Bernstein MA and Welch SP: mu-Opioid receptor down-regulation and cAMP-dependent protein kinase phosphorylation in a mouse model of chronic morphine tolerance. Brain Res Mol Brain Res 55: 237-242, 1998.

65. Stafford K, Gomes AB, Shen J and Yoburn BC: mu-Opioid receptor downregulation contributes to opioid tolerance in vivo. Pharmacol Biochem Behav 69: 233-237, 2001.

66. Fábián G, Bozó B, Szikszay M, Horváth G, Coscia CJ and Szücs M: Chronic morphine-induced changes in mu-opioid receptors and $\mathrm{G}$ proteins of different subcellular loci in rat brain. J Pharmacol Exp Ther 302: 774-780, 2002.

67. Gupta S and Kulhara P: Cellular and molecular mechanisms of drug dependence: An overview and update. Indian J Psychiatry 49: 85-90, 2007.

68. Chakrabarti S, Liu NJ and Gintzler AR: Phosphorylation of unique $\mathrm{C}$-terminal sites of the mu-opioid receptor variants $1 \mathrm{~B} 2$ and $1 \mathrm{C} 1$ influences their Gs association following chronic morphine. J Neurochem 152: 449-467, 2020.

69. Kelley N, Jeltema D, Duan Y and He Y: The NLRP3 inflammasome: An overview of mechanisms of activation and regulation. Int J Mol Sci 20: 3328, 2019.

70. Jha MK, Jeon S and Suk K: Glia as a link between neuroinflammation and neuropathic pain. Immune Netw 12: 41-47, 2012.

71. Pinho-Ribeiro FA, Verri WA Jr and Chiu IM: Nociceptor sensory neuron-immune interactions in pain and inflammation. Trends Immunol 38: 5-19, 2017.

72. Shavit Y, Wolf G, Goshen I, Livshits D and Yirmiya R Interleukin-1 antagonizes morphine analgesia and underlies morphine tolerance. Pain 115: 50-59, 2005.

73. Lacagnina MJ, Watkins LR and Grace PM: Toll-like receptors and their role in persistent pain. Pharmacol Ther 184: 145-158, 2018.

74. Eidson LN, Inoue K, Young LJ, Tansey MG and Murphy AZ: Toll-like receptor 4 mediates morphine-induced neuroinflammation and tolerance via soluble tumor necrosis factor signaling. Neuropsychopharmacology 42: 661-670, 2017.

75. Illes P, Rubini P, Ulrich H, Zhao Y and Tang Y: Regulation of microglial functions by purinergic mechanisms in the healthy and diseased CNS. Cells 9: 1108,2020. 
76. Mohan S, Davis RL, DeSilva U and Stevens CW: Dual regulation of mu opioid receptors in SK-N-SH neuroblastoma cells by morphine and interleukin-1beta: Evidence for opioid-immune crosstalk. J Neuroimmunol 227: 26-34, 2010.

77. Ruzicka BB and Akil H: The interleukin-lbeta-mediated regulation of proenkephalin and opioid receptor messenger RNA in primary astrocyte-enriched cultures. Neuroscience 79: 517-524, 1997.

78. Liu DQ, Zhou YQ and Gao F: targeting cytokines for morphine tolerance: A narrative review. Curr Neuropharmacol 17: 366-376, 2019.

79. Allan SM, Tyrrell PJ and Rothwell NJ: Interleukin-1 and neuronal injury. Nat Rev Immunol 5: 629-640, 2005.

80. Park JI, Strock CJ, Ball DW and Nelkin BD: Interleukin-1beta can mediate growth arrest and differentiation via the leukemia inhibitory factor/JAK/STAT pathway in medullary thyroid carcinoma cells. Cytokine 29: 125-134, 2005.

81. Chen ML, Cao H, Chu YX, Cheng LZ, Liang LL, Zhang YQ and Zhao ZQ: Role of P2X7 receptor-mediated IL-18/IL-18R signaling in morphine tolerance: Multiple glial-neuronal dialogues in the rat spinal cord. J Pain 13: 945-958, 2012.

82. Janeway CA Jr and Medzhitov R: Innate immune recognition. Annu Rev Immunol 20: 197-216, 2002.

83. Akira S, Uematsu S and Takeuchi O: Pathogen recognition and innate immunity. Cell 124: 783-801, 2006.

84. Hutchinson MR, Zhang Y, Shridhar M, Evans JH, Buchanan MM Zhao TX, Slivka PF, Coats BD, Rezvani N, Wieseler J, et al: Evidence that opioids may have toll-like receptor 4 and MD-2 effects. Brain Behav Immun 24: 83-95, 2010.

85. Eidson LN and Murphy AZ: Blockade of Toll-like receptor 4 attenuates morphine tolerance and facilitates the pain relieving properties of morphine. J Neurosci 33: 15952-15963, 2013.

86. Liu Y, Dai Y, Li Q, Chen C, Chen H, Song Y, Hua F and Zhang Z: Beta-amyloid activates NLRP3 inflammasome via TLR4 in mouse microglia. Neurosci Lett 736: 135279, 2020.

87. de Rivero Vaccari JP, Dietrich WD and Keane RW: Activation and regulation of cellular inflammasomes: Gaps in our knowledge for central nervous system injury. J Cereb Blood Flow Metab 34: 369-375,2014.
88. Kleibeuker W, Gabay E, Kavelaars A, Zijlstra J, Wolf G, Ziv N, Yirmiya R, Shavit Y, Tal M and Heijnen CJ: IL-1 beta signaling is required for mechanical allodynia induced by nerve injury and for the ensuing reduction in spinal cord neuronal GRK2. Brain Behav Immun 22: 200-208, 2008.

89. Grace PM, Loram LC, Christianson JP, Strand KA, Flyer-Adams JG, Penzkover KR, Forsayeth JR, van Dam AM, Mahoney MJ, Maier SF, et al: Behavioral assessment of neuropathic pain, fatigue, and anxiety in experimental autoimmune encephalomyelitis (EAE) and attenuation by interleukin-10 gene therapy. Brain Behav Immun 59: 49-54, 2017.

90. Grace PM, Strand KA, Galer EL, Urban DJ, Wang X, Baratta MV, Fabisiak TJ, Anderson ND, Cheng K, Greene LI, et al: Morphine paradoxically prolongs neuropathic pain in rats by amplifying spinal NLRP3 inflammasome activation. Proc Natl Acad Sci USA 113: E3441-E3450, 2016.

91. Cunha TM, Roman-Campos D, Lotufo CM, Duarte HL, Souza GR, Verri WA Jr, Funez MI, Dias QM, Schivo IR, Domingues AC, et al: Morphine peripheral analgesia depends on activation of the PI3Kgamma/AKT/nNOS/NO/KATP signaling pathway. Proc Natl Acad Sci USA 107: 4442-4447, 2010.

92. Roeckel LA, Le Coz GM, Gaveriaux-Ruff C and Simonin F: Opioid-induced hyperalgesia: Cellular and molecular mechanisms. Neuroscience 338: 160-182, 2016.

93. Jeffery MM, Chaisson CE, Hane C, Rumanes L, Tucker J, Hang L, McCoy R, Chen CL, Bicket MC, Hooten WM, et al: Assessment of potentially inappropriate prescribing of opioid analgesics requiring prior opioid tolerance. JAMA Netw Open 3: e202875, 2020. 